\title{
Calculations of automatic chamber flux measurements of methane and carbon dioxide using short time series of concentrations
}

\author{
Norbert Pirk $^{1,2}$, Mikhail Mastepanov ${ }^{1,3}$, Frans-Jan W. Parmentier ${ }^{1,3}$, Magnus Lund ${ }^{1,3}$, Patrick Crill ${ }^{4}$, and \\ Torben R. Christensen ${ }^{1,3}$ \\ ${ }^{1}$ Department of Physical Geography and Ecosystem Science, Lund University, Lund, Sweden \\ ${ }^{2}$ Geology Department, University Centre in Svalbard, Longyearbyen, Norway \\ ${ }^{3}$ Arctic Research Centre, Aarhus University, Aarhus, Denmark \\ ${ }^{4}$ Department of Geological Sciences, Stockholm University, Stockholm, Sweden \\ Correspondence to: Norbert Pirk (norbert.pirk@nateko.lu.se)
}

Received: 22 May 2015 - Published in Biogeosciences Discuss.: 4 September 2015

Revised: 25 January 2016 - Accepted: 2 February 2016 - Published: 18 February 2016

\begin{abstract}
The closed chamber technique is widely used to measure the exchange of methane $\left(\mathrm{CH}_{4}\right)$ and carbon dioxide $\left(\mathrm{CO}_{2}\right)$ from terrestrial ecosystems. There is, however, large uncertainty about which model should be used to calculate the gas flux from the measured gas concentrations. Due to experimental uncertainties the simple linear regression model (first-order polynomial) is often applied, even though theoretical considerations of the technique suggest the application of other, curvilinear models. High-resolution automatic chamber systems which sample gas concentrations several hundred times per flux measurement make it possible to resolve the curvilinear behavior and study the information imposed by the natural variability of the temporal concentration changes. We used more than 50000 such flux measurements of $\mathrm{CH}_{4}$ and $\mathrm{CO}_{2}$ from five field sites located in peatforming wetlands ranging from 56 to $78^{\circ} \mathrm{N}$ to quantify the typical differences between flux estimates of different models. In addition, we aimed to assess the curvilinearity of the concentration time series and test the general applicability of curvilinear models. Despite significant episodic differences between the calculated flux estimates, the overall differences are generally found to be smaller than the local flux variability on the plot scale. The curvilinear behavior of the gas concentrations within the chamber is strongly influenced by wind-driven chamber leakage, and less so by changing gas concentration gradients in the soil during chamber closure. Such physical processes affect both gas species equally, which makes it possible to isolate biochemical processes affecting the gases differently, such as photosynthesis limita-
\end{abstract}

tion by chamber headspace $\mathrm{CO}_{2}$ concentrations under high levels of incoming solar radiation. We assess the possibility to exploit this effect for a partitioning of the net $\mathrm{CO}_{2}$ flux into photosynthesis and ecosystem respiration as an example of how high-resolution automatic chamber measurements could be used for purposes beyond the estimation of the net gas flux. This shows that while linear and curvilinear calculation schemes can provide similar net fluxes, only curvilinear models open additional possibilities for high-resolution automatic chamber measurements.

\section{Introduction}

To understand the role of wetlands within the global carbon cycle, accurate estimations of the fluxes of methane $\left(\mathrm{CH}_{4}\right)$ and carbon dioxide $\left(\mathrm{CO}_{2}\right)$ between the surface and the atmosphere are essential (McGuire et al., 2012). Gas exchange measurements are often made with the closed, non-steadystate chamber technique whereby a chamber is placed on top of the soil for a short interval and the change in gas concentrations in the chamber headspace is monitored over time. The resulting time series of gas concentration measurements makes it possible to estimate the surface-atmosphere exchange with the plot on which the chamber was installed. This is often done using first-order polynomial linear regression, even though the change in gas concentration might be curvilinear. A number of factors can influence the temporal changes in the gas concentration in a systematic manner that 
can lead to the development of the curvilinear change in the concentration. For example, the increase of temperature and humidity inside the closed chamber can affect biological processes (e.g., increase respiration, decrease photosynthesis) as well as the gas concentration measurements, which can lead to an apparent saturation of the increase. The same is true for the extraction of gas samples for analysis, and leaks in the chamber construction or installation by which enclosed air can mix with ambient air.

Also, the temporal increase might appear to saturate because the vertical concentration gradient between the soil and the chamber headspace lessens as a result of accumulation in the chamber. This effect was theoretically described using diffusion theory by Hutchinson and Mosier (1981). The more recent non-steady-state diffusive flux estimator (NDFE) model is built around the same argument of an altered gas concentration gradient in the soil and has proven to perform well in computer simulations (Healy et al., 1996). The NDFE model captures the diffusive pathways of gas transport in the soil and has thus been applied in different experiments including flux measurements of $\mathrm{CO}_{2}$ (e.g., Kutzbach et al., 2007) and $\mathrm{CH}_{4}$ (e.g., Forbrich et al., 2010). The additional curvature parameter of such diffusion-based models is of particular interest, because it holds information about the processes of gas transport in the soil, which could be used to additionally characterize site conditions, for example, to assess the effect of vascular plant abundance on gas transport (Ström et al., 2005). Such flux models, however, disregard ebullitive gas transport, which has to be analyzed using different methods (e.g., Goodrich et al., 2011). Moreover, it is an open question whether the effect of an altered concentration gradient is important under field conditions, and it is hard to uncouple this effect from other episodic sources of changes.

The choice of flux model can be one of the largest sources of uncertainty for chamber flux measurements (Levy et al., 2011). In this process, log-linear or higher-order polynomial models often yield significantly elevated fluxes, but the additional parameter of the fit (curvature) makes them vulnerable to noise in the measurements. It has therefore been proposed to analyze the quality of fit of several models for every flux measurement and to use the result of the model which gives the best description of the gas concentration change (Forbrich et al., 2010; Pedersen et al., 2010; Kutzbach et al., 2007). The present study, on the other hand, analyzes the resulting flux time series of different models separately and compares them to reference linear estimates reported by the sites. We attempt to explain the apparent differences with environmental conditions and, thus, investigate the processes affecting the evolution of the headspace gas concentrations. The simultaneous analysis of $\mathrm{CH}_{4}$ and $\mathrm{CO}_{2}$ curvatures could make it possible to isolate biological and physical processes, and thereby exploit the information for the purpose of $\mathrm{CO}_{2}$ flux partitioning into photosynthesis and ecosystem respiration.
Here, we aim to improve the understanding of the processes leading to curvilinear concentration time series of chamber flux measurements and quantify differences between flux estimates derived from different models. We hypothesize that the curvature of the concentration time series is in part caused by systematic effects of the closed chamber technique, and that these are related to the environmental site conditions. Such an analysis can only be meaningful if random experimental uncertainties are kept to a minimum. We achieve this by using data from high-resolution automatic chamber systems installed to monitor $\mathrm{CH}_{4}$ and $\mathrm{CO}_{2}$ fluxes at five natural wetland sites, ranging from the high Arctic down to the mid-latitudes. These sites feature comparable but slightly different measurement configurations, and all have sufficient resolution in time and concentration to resolve the curvature within the concentration changes. Beside the ecological differences between sites, they also employ slightly different methods to calculate the fluxes they report, which we use to assess the differences of the flux estimation methods.

\section{Materials and methods}

\subsection{Study sites}

The five study sites are all situated in peat-forming wetlands where the water table is typically close to the soil surface. Table 1 shows an overview of their locations, long-term temperature and precipitation, the ecosystem type, as well as the year in which the data used in the present study were recorded. These sites span about 22 latitudinal degrees in the north atlantic region and hence cover a wide range of climatic conditions. The ground thermal regime at the sites ranges from continuous permafrost at Adventdalen (with icewedge polygons) and Zackenberg, to sporadic and isolated permafrost at Stordalen and Kobbefjord, to no permafrost at Fäjemyr. Apart from Fäjemyr, which is a mid-latitude bog, all sites are located in the arctic or subarctic tundra. The vegetation at all sites is dominated by typical wetland species such as Eriophorum spp. and Dupontia spp. with a varying subcanopy of mosses (Sphagnum spp.).

\subsection{Experimental setup}

All field sites are equipped with a similar automatic chamber system based on Goulden and Crill (1997). Adventdalen, Zackenberg, Kobbefjord, and Fäjemyr all feature the same setup: a set of six transparent chambers (each covering a square of $60 \mathrm{~cm}$ by $60 \mathrm{~cm}$, with a height of $30 \mathrm{~cm}$ ) are placed at representative locations at each site. Inside each chamber there is a fan for ventilation and gas mixing. A pair of high-density polyethylene tubes ( $4 \mathrm{~mm}$ inner diameter) connect each chamber to the gas analyzers, which consists of a nondestructive $\mathrm{CO}_{2}$ analyzer (SBA-4, PP Systems, UK) and a likewise nondestructive $\mathrm{CH}_{4}$ analyzer (DLT100, Los Gatos 

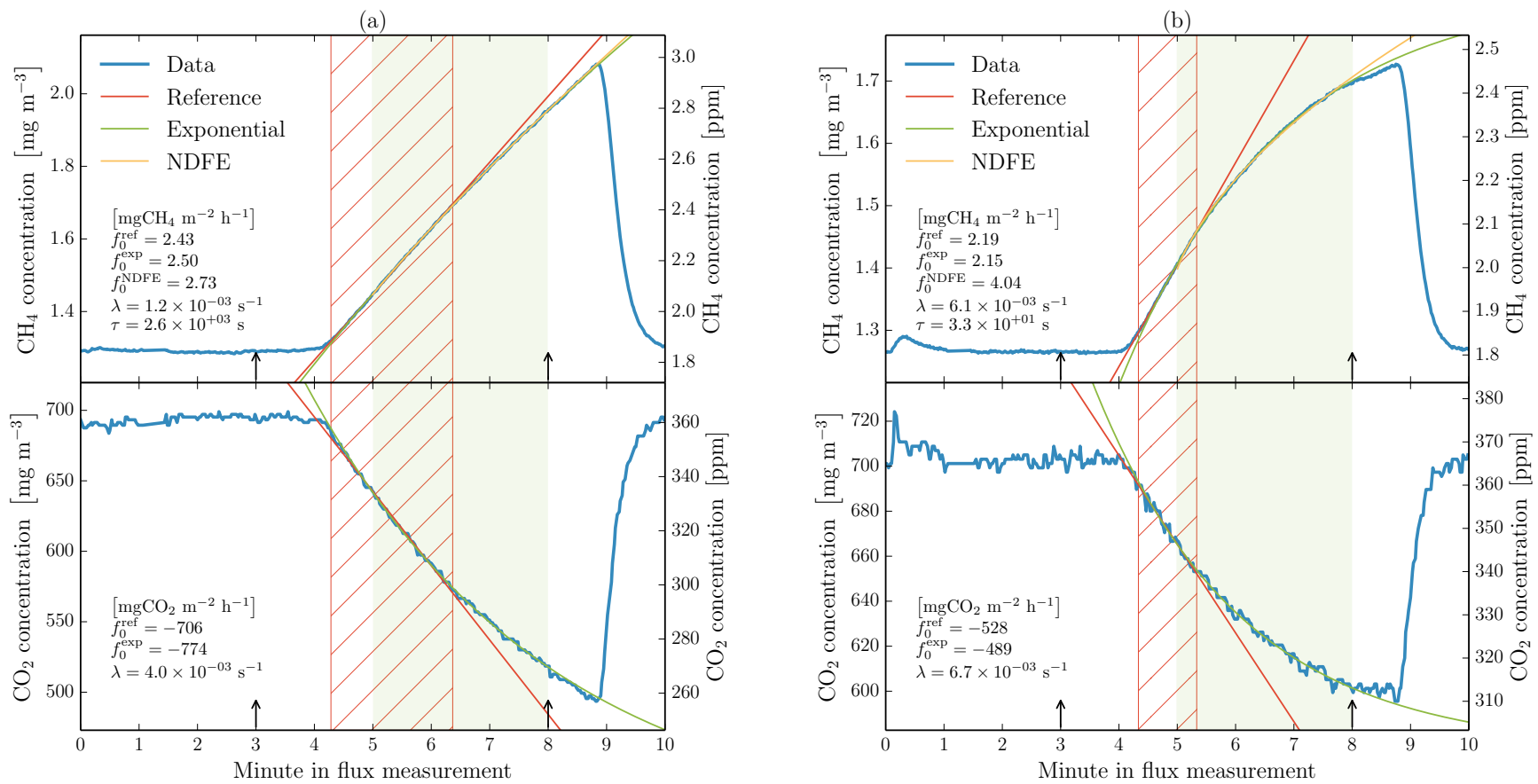

Figure 1. Two examples of $\mathrm{CH}_{4}$ (top) and $\mathrm{CO}_{2}$ (bottom) flux measurements. (a) Chamber 6 at Zackenberg on 12 July 2010, 09:50 LT (hourly average wind speed $1.8 \mathrm{~m} \mathrm{~s}^{-1}$ ). (b) Same chamber on 2 July 2010, 13:50 LT (hourly average wind speed $4.5 \mathrm{~m} \mathrm{~s}^{-1}$ ). The arrows indicate chamber closing and opening time. The red hatched band indicates the time window used for the linear fit of the reference (Mastepanov et al., 2013). The shaded green band indicates the fixed 3 min window used for the curvilinear fits.

Table 1. Site overview, from north to south. Temperature and precipitation are average values of measurements by the closest weather station in the period 1961-1990 (1958-1987 for Zackenberg).

\begin{tabular}{lllllll}
\hline Site & Location & Coordinates & Air temp. & Precipitation & Ecosystem type & Data year \\
\hline Adventdalen & Svalbard & $78^{\circ} 11^{\prime} \mathrm{N}, 15^{\circ} 55^{\prime} \mathrm{E}$ & $-6.7^{\circ} \mathrm{C}$ & $190 \mathrm{~mm} \mathrm{yr}^{-1}$ & Fen & 2013 \\
Zackenberg & NE Greenland & $74^{\circ} 30^{\prime} \mathrm{N}, 21^{\circ} 00^{\prime} \mathrm{W}$ & $-9.9^{\circ} \mathrm{C}$ & $286 \mathrm{~mm} \mathrm{yr}^{-1}$ & Fen & 2010 \\
Stordalen & N Sweden & $68^{\circ} 22^{\prime} \mathrm{N}, 19^{\circ} 03^{\prime} \mathrm{E}$ & $-0.8^{\circ} \mathrm{C}$ & $304 \mathrm{~mm} \mathrm{yr}^{-1}$ & Mixed peatland & 2012 \\
Kobbefjord & W Greenland & $64^{\circ} 08^{\prime} \mathrm{N}, 52^{\circ} 23^{\prime} \mathrm{W}$ & $-1.4^{\circ} \mathrm{C}$ & $752 \mathrm{~mm} \mathrm{yr}^{-1}$ & Fen & 2012 \\
Fäjemyr & S Sweden & $56^{\circ} 15^{\prime} \mathrm{N}, 13^{\circ} 33^{\prime} \mathrm{E}$ & $6.2^{\circ} \mathrm{C}$ & $700 \mathrm{~mm} \mathrm{yr}^{-1}$ & $\mathrm{Bog}$ & 2008 \\
\hline
\end{tabular}

Research, USA). Sample air is pumped from the chamber, through the gas analyzer and back to the chamber at a rate of $0.4 \mathrm{~L} \mathrm{~min}^{-1}$. Primary $\mathrm{CH}_{4}$ concentrations are recorded at $1.0 \mathrm{~Hz}$, and primary $\mathrm{CO}_{2}$ concentrations are recorded at a slightly lower rate of $0.625 \mathrm{~Hz}$. The computer running these automatic measurements activates the chambers in succession for $10 \mathrm{~min}$. During the first $3 \mathrm{~min}$ the chamber is open for ventilation, then closed for $5 \mathrm{~min}$, and then opened again for the last $2 \mathrm{~min}$. Thus each chamber is activated once per hour while the five inactive chambers remain open.

At Stordalen there are nine transparent chambers that are activated for $18 \mathrm{~min}$ at a time. This results in a $3 \mathrm{~h}$ cycle (one $18 \mathrm{~min}$ slot is used as a control with ambient air). The chamber closure time is $5 \mathrm{~min}$, between minute 10 and 15 of each measurement. The construction of the chambers is different from the other sites. The entire chamber is lifted off plots with short canopies $(<20 \mathrm{~cm})$, and a similar $20 \mathrm{~cm}$ portion is lifted off collars installed in habitats with taller vegetation. Another important difference to the other sites is that Stordalen does not use fans inside the chambers, which could lead to more variability in the measured concentrations. Mixing within the chamber is due to flow $\left(2 \mathrm{~L} \mathrm{~min}^{-1}\right)$ between the sample return manifold and the sample outlet port. A small subflow is diverted to a cavity ring-down laser spectrometer (DLT-100, 908-011, Los Gatos Research, USA) used for concentration analysis at a rate of $1.0 \mathrm{~Hz}$ for both $\mathrm{CH}_{4}$ and $\mathrm{CO}_{2}$.

Examples of the recorded data are shown in Fig. 1, for both $\mathrm{CH}_{4}$ and $\mathrm{CO}_{2}$ (see Supplement for more examples from other sites). An initial equilibration phase is apparent during the first few minutes after which the baseline stabilizes. Due to the distance between chambers and the gas analyzer there 
is a time delay between chamber closure and the start of the flux measurement. To allow for robust and automated processing we decided to use a fixed 3 min window when fitting models to the data. This window starts 2 min after closure (to account for the time delay) and ends at chamber opening, which ensures that all included concentration measurements were taken while the chamber was closed. This approach will always exclude parts of the flux measurement, but it still leaves 180 concentration measurements for $\mathrm{CH}_{4}$ and at least 112 for $\mathrm{CO}_{2}$.

The air temperature $(T)$ and pressure $(P)$ used in the flux calculations were recorded by sensors in the vicinity of the chambers. For the sake of comparability, we only use flux measurements recorded in June, July, and August of the respective year of each site.

\subsection{Flux models}

The linear model assumes a constant concentration change, i.e.,

$$
\frac{\mathrm{d} c(t)}{\mathrm{d} t}=\left(\frac{A}{V}\right) f_{0}
$$

where $c(t)$ is the gas concentration in time, $f_{0}$ is the (initial, pre-deployment) gas flux which is assumed to be constant during closure time, $A$ is the area which is covered by the chamber, and $V$ is the (effective, free) volume of the chamber. Note that gas concentrations are typically measured as a molar fraction (e.g., in units of ppm) and have to be converted to volumetric mass density (e.g., $\mathrm{mg} \mathrm{m}^{-3}$ ) by means of the ideal gas (using $T$ and $P$ ) law before Eq. (1) can be applied. This approach neglects the presence of water vapor (which is not monitored in the chamber headspace) and the corresponding dilution effect on the measurements, which leads to an underestimation of the calculated fluxes which depends on flux magnitude, relative humidity, and temperature in the chamber headspace but is typically within 1-2\% (see Supplement for details). Solving this differential equation leads to the linear model

$c(t)=\left(\frac{A}{V}\right) f_{0} t+c_{0}$,

where the integration constant $c_{0}$ represents the ambient atmospheric (pre-deployment) concentration of the respective gas.

We extend the linear model of Eq. (1) with a term counteracting any change of gas concentration from the ambient concentration in a linear fashion, i.e.,

$\frac{\mathrm{d} c(t)}{\mathrm{d} t}=\left(\frac{A}{V}\right) f_{0}-\lambda\left(c(t)-c_{0}\right)$,

where the constant $\lambda$ (in units of time ${ }^{-1}$ ) describes the sum of all processes which are proportional to the concentration difference $\Delta c(t)=c(t)-c_{0}$. If no curvature is present, i.e., $\lambda=0$, this model reduces to the linear model. Equation (3) is solved by the function

$c(t)=\left(\frac{A}{V}\right) \frac{f_{0}}{\lambda}\left(1-e^{-\lambda t}\right)+c_{0}$,

which defines the score function of this, hereafter referred to as exponential model. It is based on the assumption that curvature is proportional to $\Delta c(t)$, but it does not a priori assume any process to be responsible for the curvature. Other authors have taken the opposite approach by identifying the relevant processes first, and through the assumption of their proportionality to $\Delta c(t)$ derived the exponential form of the $c(t)$ score function (e.g., Pedersen et al., 2010; Kutzbach et al., 2007). For example, the curvature of the $\mathrm{CO}_{2}$ flux measurement $\left(\lambda_{\mathrm{CO}_{2}}\right)$ can be decomposed into three independent constants describing leakage, diffusivity in the soil profile, and the saturation of photosynthesis under high sunlight conditions where photosynthesis is assumed to be limited by $\mathrm{CO}_{2}$ concentrations inside the chamber (Kutzbach et al., 2007). For this last effect, it has been shown that the relationship between the high sunlight photosynthetic flux, $F_{\mathrm{p}}$, and the surrounding $\mathrm{CO}_{2}$ concentration is approximately linear in the relevant range of $\mathrm{CO}_{2}$ concentrations (Farquhar et al., $1980)$, i.e., $F_{\mathrm{p}}(t)=k_{\mathrm{p}} c(t)\left(\frac{V}{A}\right)$, where $k_{\mathrm{p}}$ is the constant of proportionality. As the $\mathrm{CO}_{2}$ concentration in the chamber headspace decreases during the closure time, $F_{\mathrm{p}}$ decreases correspondingly. This interaction is captured by the exponential model and would result in an increased $\mathrm{CO}_{2}$ curvature at high levels of sunlight, or photosynthetically active radiation (PAR). This also means that if $k_{\mathrm{p}}$ can be isolated from $\lambda, F_{\mathrm{p}}$ can be estimated from the curvature of the measurement and thereby achieve a $\mathrm{CO}_{2}$ flux partitioning.

The non-steady-state diffusive flux estimator (NDFE) model (e.g., Healy et al., 1996) is implemented as

$c(t)=\left(\frac{A}{V}\right) f_{0} \tau\left[\frac{2}{\sqrt{\pi}} \sqrt{t / \tau}+e^{t / \tau} \operatorname{erfc}(\sqrt{t / \tau})-1\right]+c_{0}$,

where the curvature parameter $\tau$ (in units of time) measures how fast the changed gas concentration gradient propagates through the soil. Like other authors (e.g., Kutzbach et al., 2007) we restrict the application of the NDFE model to exclusively positive fluxes (gas sources), i.e., our $\mathrm{CH}_{4}$ measurements.

These models are optimized against the measured concentrations with a least-squares algorithm based on the Levenberg-Marquardt algorithm. The values of all other variables entering the flux calculation $(A, V, T, P)$ are the same for all models.

\subsection{Reference linear estimates}

We compare the curvilinear flux estimates derived from the fixed 3 min window of the flux measurement to flux estimates calculated from the same raw data in other studies. Different versions of the linear regression method (cf. Eq. 2) were used 


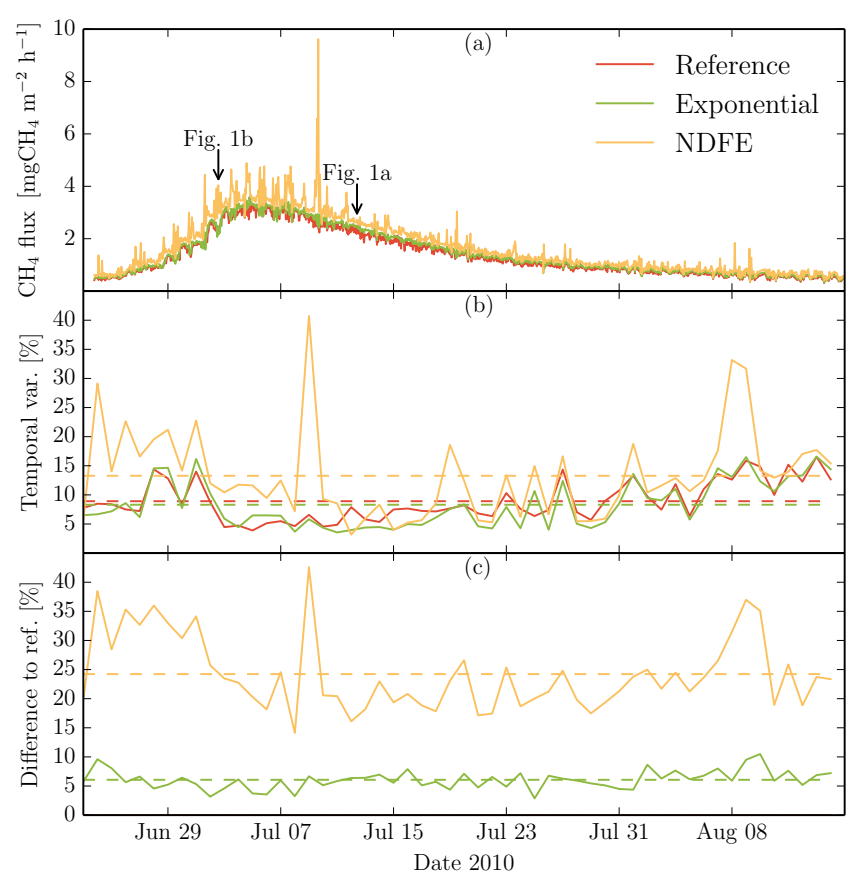

Figure 2. Results of chamber 6 at Zackenberg. (a) $\mathrm{CH}_{4}$ flux in measurement time resolution (hourly). The arrows indicate the two examples of Fig. 1. (b) Flux temporal variability expressed as daily standard deviation divided by daily mean. (c) Mean daily ratio with respect to the reference data. Dashed lines indicate mean values of the entire time series.

to calculate these estimates at each site, which are hereafter referred to as reference linear estimates.

At Zackenberg, a linear regression to the initial, mostlinear, part of the gas concentration curve was applied by careful visual inspection of each measurement (Mastepanov et al., 2013). The same approach was used for the Kobbefjord (Jensen and Rasch, 2013) and Fäjemyr (Lund, 2009) reference fluxes.

At Stordalen, the algorithm first block-averages the raw data to $15 \mathrm{~s}$ resolution and then calculates eight sequential $2.25 \mathrm{~min}$ long fits starting every $15 \mathrm{~s}$ (Bäckstrand et al., 2008). The most linear (highest $R^{2}$ ) of these eight fits is used for $\mathrm{CH}_{4}$ flux calculation and the steepest one for $\mathrm{CO}_{2}$ uptake situation (usually during the day). This procedure is designed to avoid saturation effects.

For Adventdalen (the most recent site) we did not have independently calculated reference fluxes. Instead, we applied linear regression to the same 3 min time window which was used for the curvilinear models. Consequently, Adventdalen yields the direct comparison between linear and curvilinear flux estimates, without additional effects of the fit window choice or block averaging.

\section{Results and discussion}

\subsection{Flux estimates}

Figure 2 shows a typical example of the $\mathrm{CH}_{4}$ flux estimates. Both curvilinear models give reasonable results with a comparable magnitude to the reference data. There are, however, clear spikes in the NDFE flux estimate which lead to a significantly higher temporal variability compared to both reference and exponential flux estimates. True natural $\mathrm{CH}_{4}$ emissions are not expected to fluctuate so strongly under these conditions in summertime. The spikes do not relate to ebullition events but instead coincide with measurements with strong curvature (low $\tau$ ), exemplified by the two examples from chamber 6 at Zackenberg (shown in Fig. 1), which are marked by the arrows in Fig. 2. This unrealistic $\mathrm{CH}_{4}$ flux pattern of the NDFE model suggests a violation of the underlying assumption of the model, i.e., that curvature cannot generally be attributed to the altered gas concentration gradient in the soil profile.

Unlike in the NDFE model, curvature $(\lambda)$ and flux are uncoupled in our exponential model, demonstrated by the stable flux results, which are independent of curvature strength. In the example shown in Fig. 2 the exponential model yields on average about $7 \%$ flux increase compared to the reference data, while the NDFE model gives about $24 \%$ higher fluxes than the reference - more or less independent of the absolute flux magnitude.

An alternative way to quantify the differences between two flux models (for example reference and exponential) is to assume a constant ratio, i.e., $f_{0}^{\text {ref }}\left(f_{0}^{\exp }\right)=a f_{0}^{\text {exp }}$, and estimate the ratio $a$ by a least-squares fit. To avoid a strong influence of a few outliers on the fit we filtered out the highest and lowest $3 \%$ of the fluxes before fitting. Figure 3 shows the result for reference and exponential flux estimates for all chambers at Zackenberg combined (see Supplement for more examples from other sites). A high correspondence $\left(R^{2}>0.9\right)$ and an overall agreement of the flux magnitudes of about $3 \%$ for $\mathrm{CH}_{4}$ and $9 \%$ for $\mathrm{CO}_{2}$ is shown. Table 2 shows these summary (all chamber) statistics for all sites. It shows the effect of the different flux estimation procedures, as well as site-specific differences. At Adventdalen, where the reference linear regression is applied to the same 3 min window as the curvilinear models, the $R^{2}$ values are highest and the linear flux estimates can never give larger (absolute) values than the curvilinear models. At Zackenberg and Kobbefjord, where the reference linear estimates are derived from a time window which is manually adjusted to the initial slope, the differences between reference and exponential estimates are reduced. At Stordalen, where no fans are used to mix the air in the chamber headspace and different methods are used for positive and negative $\mathrm{CO}_{2}$ fluxes of the reference linear estimates, $R^{2}$ values are lower and hence the shown differences are less significant. For $\mathrm{CH}_{4}$, where the NDFE model can be applied, this model yields a significantly higher flux (and 

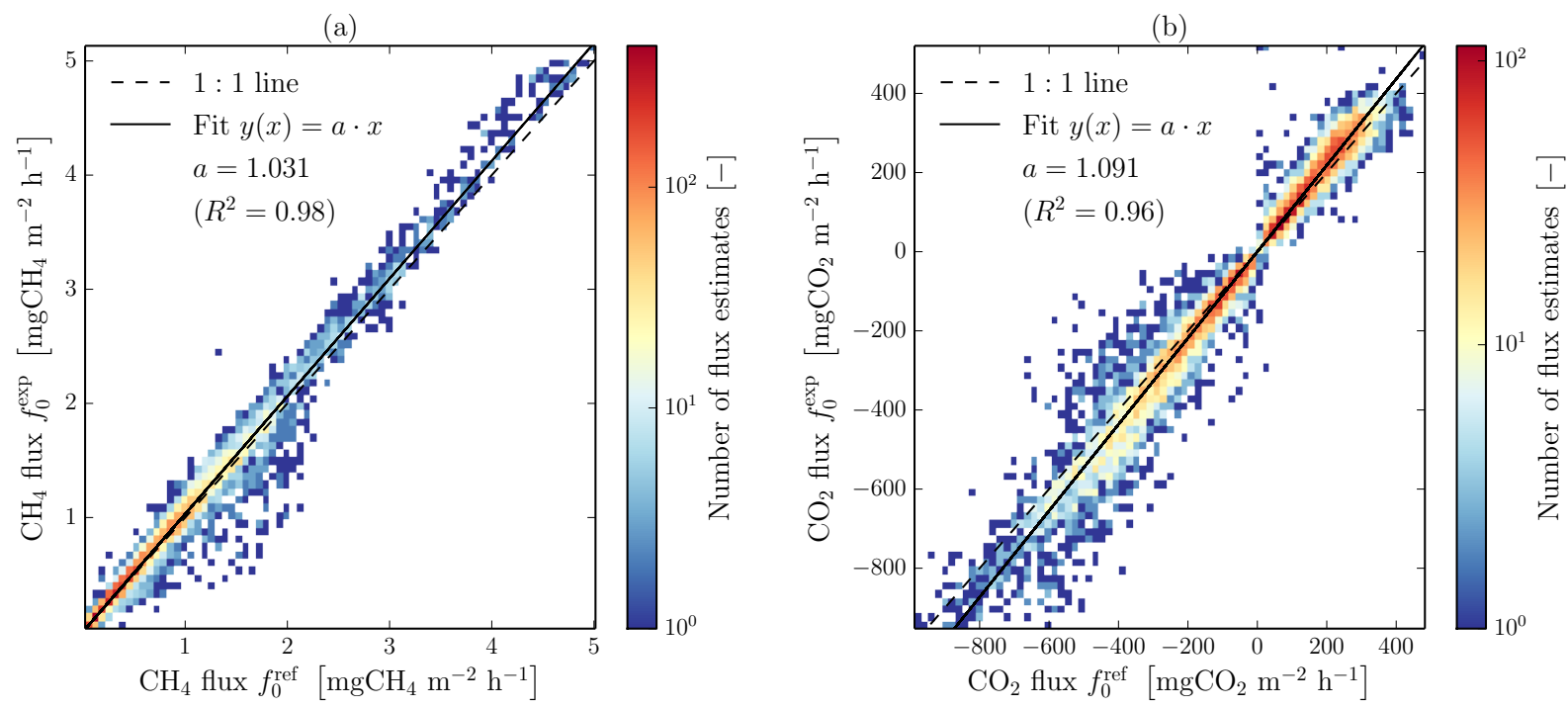

Figure 3. Example histograms of the relationship between reference and exponential flux estimates for all chambers of $\mathrm{Zackenberg}$ (a) $\mathrm{CH}_{4}$. (b) $\mathrm{CO}_{2}$.

Table 2. Summary statistics of all chambers. Temporal variability is expressed as daily standard deviation divided by daily mean (not shown for $\mathrm{CO}_{2}$ ). Spatial variability is expressed as the average over time of the ratio of standard deviation and mean of the individual chambers.

\begin{tabular}{|c|c|c|c|c|c|c|c|c|}
\hline \multirow[b]{2}{*}{ Site } & \multirow[b]{2}{*}{ Gas } & \multirow[b]{2}{*}{$\begin{array}{l}\text { Fluxes } \\
(\#)\end{array}$} & \multicolumn{2}{|c|}{ Difference to reference } & \multicolumn{3}{|c|}{ Temporal variability } & \multirow{2}{*}{$\begin{array}{r}\text { Spatial var. } \\
\text { Ref. } \\
(\%)\end{array}$} \\
\hline & & & $\begin{array}{r}\text { Exp. } \\
(\%)\left(R^{2}\right)\end{array}$ & $\begin{array}{c}\text { NDFE } \\
(\%)\left(R^{2}\right)\end{array}$ & $\begin{array}{l}\text { Ref. } \\
(\%)\end{array}$ & $\begin{array}{l}\text { Exp. } \\
(\%)\end{array}$ & $\begin{array}{c}\text { NDFE } \\
(\%)\end{array}$ & \\
\hline \multirow[t]{2}{*}{ Adventdalen } & $\mathrm{CH}_{4}$ & 1871 & $3.8(0.99)$ & $7.5(0.97)$ & 6.6 & 5.9 & 7.6 & 117.4 \\
\hline & $\mathrm{CO}_{2}$ & 1634 & $13.2(0.98)$ & - & - & - & - & 44.8 \\
\hline \multirow[t]{2}{*}{ Zackenberg } & $\mathrm{CH}_{4}$ & 7092 & $3.1(0.98)$ & $22.1(0.84)$ & 14.2 & 15.2 & 26.1 & 93.0 \\
\hline & $\mathrm{CO}_{2}$ & 7809 & $9.1(0.96)$ & - & - & - & - & 46.5 \\
\hline \multirow[t]{2}{*}{ Stordalen } & $\mathrm{CH}_{4}$ & 1071 & $5.9(0.73)$ & $120.6(0.20)$ & 27.6 & 37.8 & 73.3 & 130.3 \\
\hline & $\mathrm{CO}_{2}$ & 1640 & $-15.5(0.81)$ & - & - & - & - & 82.2 \\
\hline \multirow[t]{2}{*}{ Kobbefjord } & $\mathrm{CH}_{4}$ & 8039 & $-0.4(0.94)$ & $10.0(0.54)$ & 7.0 & 7.8 & 13.8 & 28.2 \\
\hline & $\mathrm{CO}_{2}$ & 8839 & $-6.8(0.98)$ & - & - & - & - & 40.0 \\
\hline \multirow[t]{2}{*}{ Fäjemyr } & $\mathrm{CH}_{4}$ & 6986 & $-1.4(0.83)$ & $41.3(0.00)$ & 40.1 & 40.4 & 62.6 & 71.1 \\
\hline & $\mathrm{CO}_{2}$ & 6289 & $-19.1(0.77)$ & - & - & - & - & 64.3 \\
\hline
\end{tabular}

lower $R^{2}$ ), which is probably caused by the above-described problems of this model. At Fäjemyr, where $\mathrm{CH}_{4}$ flux magnitudes are low compared to the other sites (hence lower signalto-noise ratio), the $R^{2}$ between reference and NDFE flux is particularly low. Nonetheless, the ratios between the different flux estimates are still below the typical spatial variability between the individual chambers of each respective site. So our findings suggest that the large uncertainty connected to the choice of the flux model is still exceeded by natural spatial variability on the plot scale.

\subsection{Curvature parameter $\lambda$}

We analyzed the dependency of the curvature parameter of the exponential model $\lambda$ (cf. Eq. 3) to environmental conditions, such as air temperature, pressure, solar radiation, and wind speed. As some of these variables may correlate amongst each other it can be difficult to identify the processes responsible for the observed curvature. However, throughout all sites, the ambient wind speed is found to have the strongest correlation to $\lambda$, as shown for $\mathrm{CH}_{4}$ in Fig. 4 a (see Supplement for more examples from other sites). We illustrate this with data recorded by chamber 3 in Adventdalen 2013, because it contains measurements taken with two different kinds of tape to seal the chamber on the edge of the automatically closing lid. But all other chambers show the same characteristic picture where curvature is influenced by chamber leakage driven by ambient wind speed. This experimental inevitability shows that curvature can be strongly related to other effects than the altered gas concentration gradient in the soil profile. To test whether this effect can nevertheless be seen in our data set, we use $\mathrm{CH}_{4}$ curvatures from Fäje- 
(a)

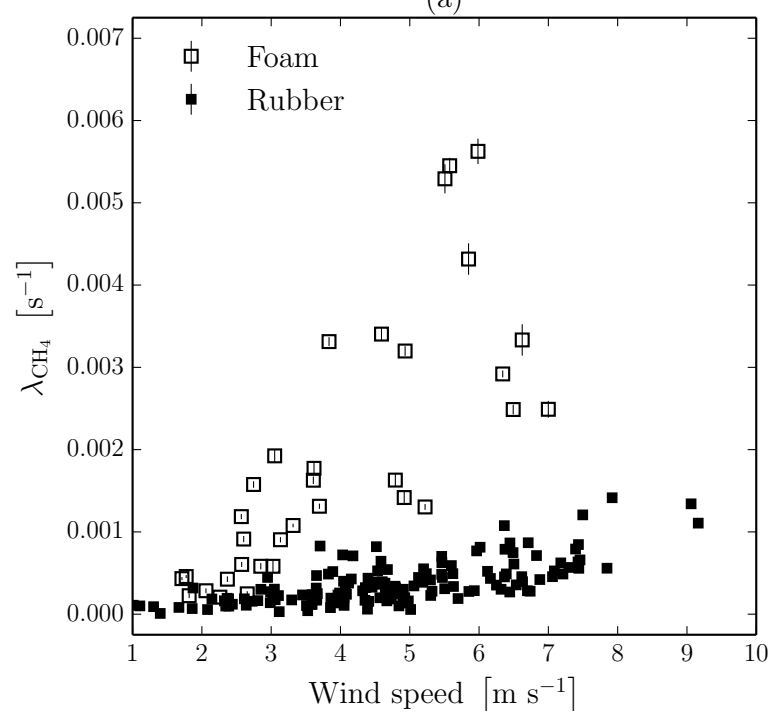

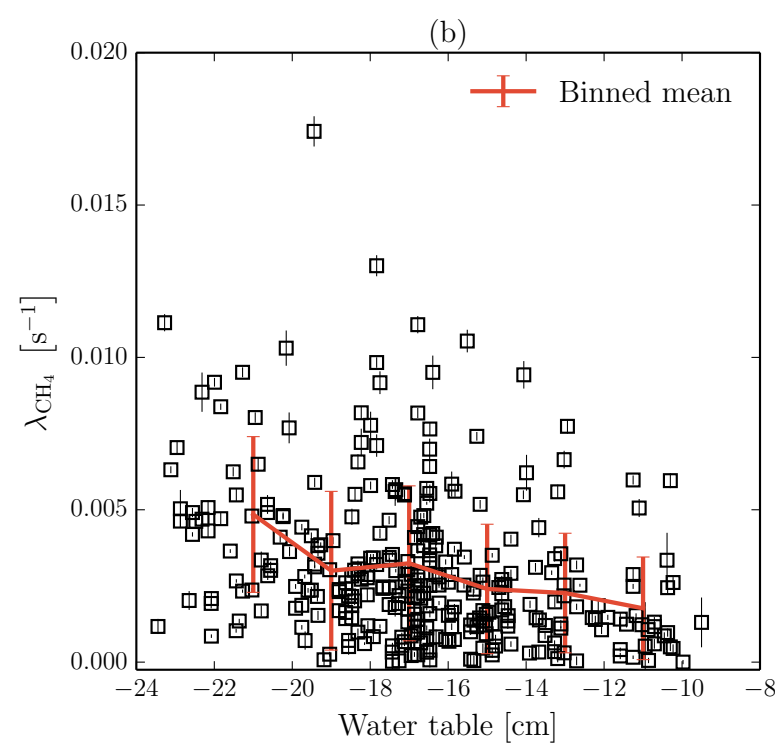

Figure 4. Curvature parameter $\lambda \mathrm{CH}_{4}$ against environmental parameters. (a) Wind speed. Data recorded by chamber 3 in Adventdalen between 26 July 2013 and 21 August 2013. On 4 August 2013 the sealing tape of the chamber lid was changed from foam to rubber, so different makers are used here for times before and after this improvement. (b) Water table position. Data from Fäjemyr between 1 June 2008 and 31 July 2008. Error bars indicate standard errors as calculated by the least-squares fit.

myr where water table height is also measured. Figure $4 \mathrm{~b}$ shows that the curvature tends to increase when the water table drops, which could be explained by a change in the gas concentration gradient, which is supposedly faster in drier soil because of the increased effective diffusivity.

\subsection{Carbon dioxide flux partitioning from curvature differences}

$\lambda_{\mathrm{CH}_{4}}$ and $\lambda_{\mathrm{CO}_{2}}$ are largely affected by the same processes, as shown by their strong correlation in Fig. 5a with data of chamber 3 at Zackenberg (see Supplement for more examples from other sites). This can be explained by physical processes, such as wind-driven leakage, which affect both gases equally. The difference $\lambda_{\mathrm{CO}_{2}}-\lambda_{\mathrm{CH}_{4}}$, on the other hand, should be sensitive to processes that affect the two gases differently. Analyzing the relationship of this curvature difference to environmental parameters, we noticed that it tends to increase above a certain level of incoming sunlight as shown in Fig. 5b. We hypothesize that this relationship is made up of a baseline, which is related to processes independent of incoming sunlight (such as the different diffusivity and gas concentration gradients), and a signal which sets in at higher levels of sunlight, when photosynthesis is supposedly limited by $\mathrm{CO}_{2}$ concentration in the chamber headspace rather than incoming sunlight. For the ecosystem of chamber 3 at Zackenberg, this increase in curvature difference starts at PAR of about 500 and levels off at about $950 \mu \mathrm{mol} \mathrm{m}^{-2} \mathrm{~s}^{-1}$. An indication of this effect could already be seen in the example of Fig. 1a, where PAR was $917 \mu \mathrm{mol} \mathrm{m}^{-2} \mathrm{~s}^{-1}$ and $\lambda_{\mathrm{CO}_{2}}>\lambda \mathrm{CH}_{4}$.
By subtracting the low PAR baseline from the curvature difference we can isolate the PAR-dependent signal in the curvature. Under conditions where photosynthesis is limited by $\mathrm{CO}_{2}$ concentrations, this can give an estimate of $k_{\mathrm{p}}$, i.e., the rate at which the $\mathrm{CO}_{2}$ flux decreases as a response to the decreasing $\mathrm{CO}_{2}$ concentrations in the chamber headspace. This means that at pre-deployment conditions $F_{\mathrm{p}}(t=0)=k_{\mathrm{p}} c_{0}\left(\frac{V}{A}\right)$, given that all environmental variables are constant during closure time. Figure 6 shows the resulting $F_{\mathrm{p}}$ estimates, as well as ecosystem respiration, $R_{\text {eco }}$, calculated from the difference to the total $\mathrm{CO}_{2}$ flux (NEE). Due to unstable environmental conditions during the closure time some partitioned fluxes have too large standard errors to confine the partitioning (corresponding to $\operatorname{error}\left(R_{\mathrm{eco}}\right)>$ $200 \mathrm{mgCO}_{2} \mathrm{~m}^{-2} \mathrm{~h}^{-1}$ ), which were here filtered out. As no nighttime fluxes are available during the summer at high Arctic sites, we compare these results to a commonly used daytime partitioning method (Lasslop et al., 2010), which models NEE as the sum of a rectangular hyperbolic lightresponse function (PAR-dependent) and the Lloyd-Taylor respiration model (temperature-dependent). Both estimates of $F_{\mathrm{p}}$ give a comparable flux, even though the uncertainty of the curvature-derived estimates are high and only a few measurements are available (stable conditions and high PAR).

Another way of verifying the partitioned fluxes derived from the curvatures is to compare $R_{\text {eco }}$ to dark measurements which were conducted during the field campaign at Zackenberg by putting a lightproof blanket over the chambers for one measurement per week. The resulting fluxes (labeled Dark in Fig. 6) tend to be lower than both model and curva- 

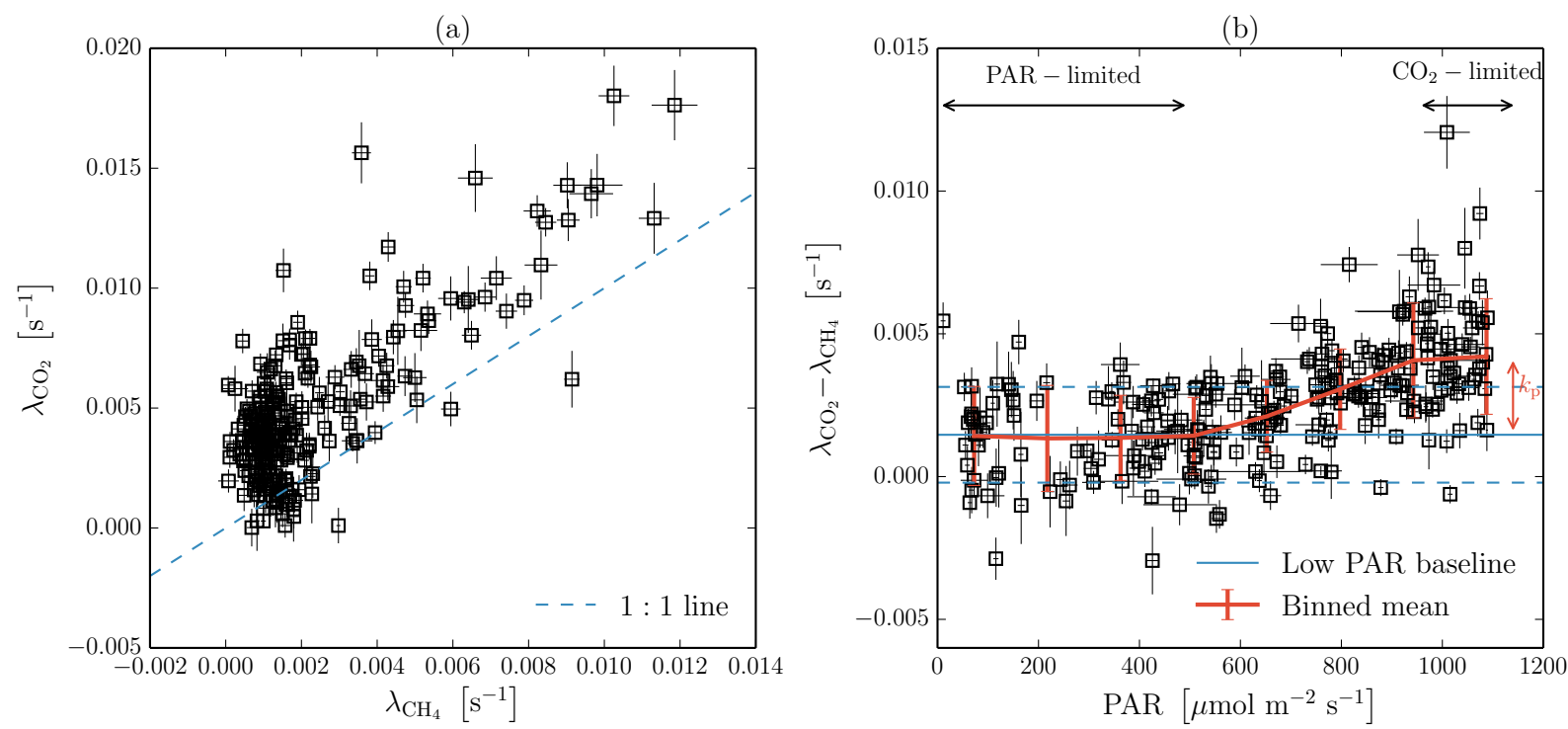

Figure 5. Example of curvature correlation (a), and curvature difference against PAR (b). All data taken from chamber 3 at Zackenberg between 17 July 2010 and 5 August 2010. Error bars indicate standard errors as calculated by the least-squares fit for $\lambda$, and the 10 min standard deviation for PAR.

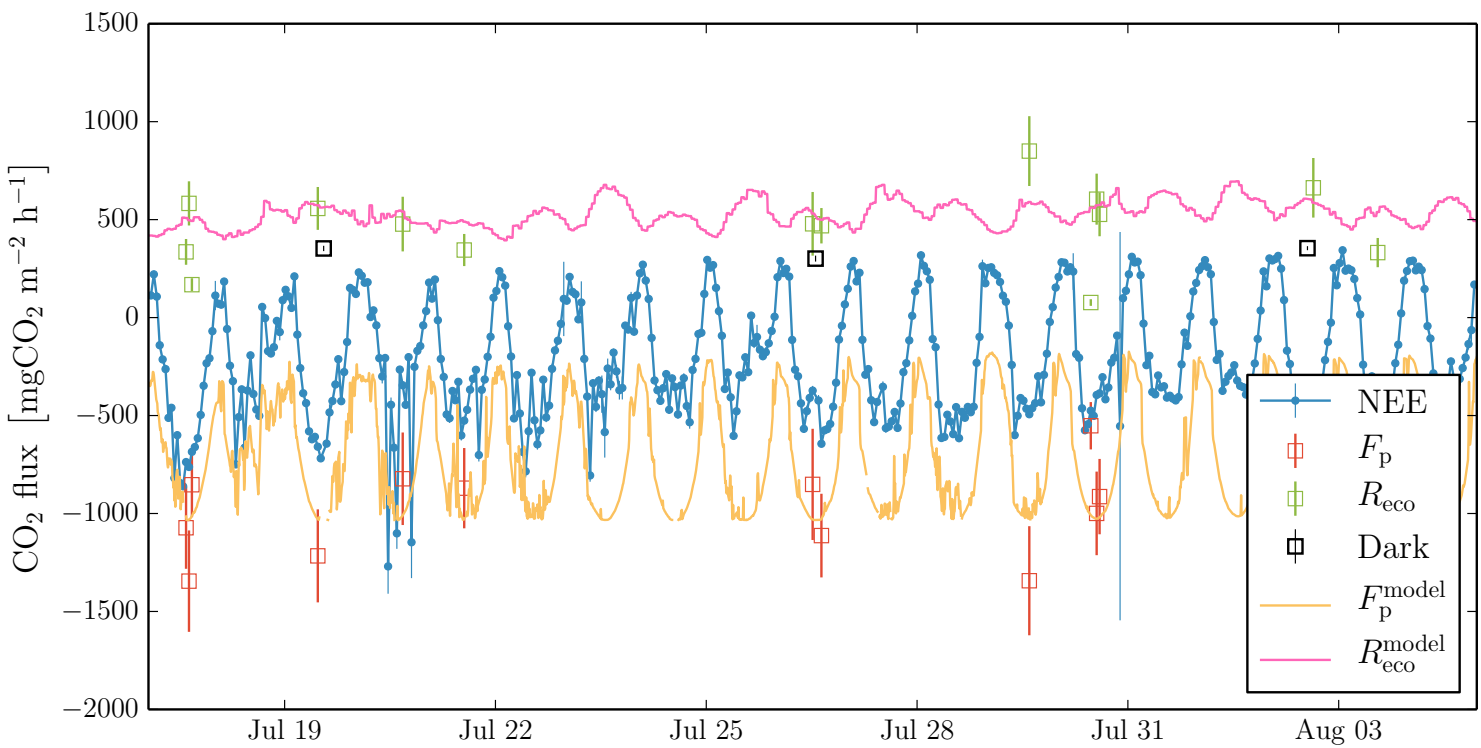

Figure 6. Example of $\mathrm{CO}_{2}$ flux partitioning based on high PAR data points of Fig. 5, i.e., from chamber 3 at Zackenberg, 2010. NEE is the total $\mathrm{CO}_{2}$ flux, $F_{\mathrm{p}}$ the photosynthesis estimate derived from the curvatures, and $R_{\mathrm{eco}}$ their difference. Dark measurements are taken with a lightproof blanket over the chamber. Modeled lines are estimates from the daytime partitioning method of Lasslop et al. (2010).

ture estimates, which could be explained by the elimination of photorespiration in dark measurements (which is included in the other two methods). On the other hand, it may also indicate the uncertainties that are connected to the different $\mathrm{CO}_{2}$ flux partitioning methods.

Note that the $\mathrm{CO}_{2}$ flux partitioning from curvature differences requires an accurate estimation of the curvature of both $\mathrm{CH}_{4}$ and $\mathrm{CO}_{2}$. Even with high-quality measurements, this can be hindered by naturally low fluxes or unstable envi- ronmental conditions. Moreover, one needs enough measurements at all levels of sunlight to see the relationship between the curvature difference and PAR and estimate the low PAR baseline. Our data of the other sites show the same characteristic picture described here, even though these limitations can impose significant uncertainty on the results and thereby limit the applicability of this partitioning method. Still, our data show that it is in principle possible to partition NEE into 
$F_{\mathrm{p}}$ and $R_{\text {eco }}$, if enough accurate estimations of $\mathrm{CH}_{4}$ and $\mathrm{CO}_{2}$ curvatures can be obtained.

\section{Conclusions}

We analyzed short time series of concentrations of automatic chamber $\mathrm{CH}_{4}$ and $\mathrm{CO}_{2}$ flux measurements from natural wetlands using different flux estimation models. Throughout all five sites included in the study, the derived curvature parameters indicate that wind-driven leakage has a strong effect on the concentration change within the chamber, which affects the various flux models differently. The linear regression model underestimates fluxes when leakage is strong, whereas the exponential model is better suited and yields fluxes very similar to those based on the initial slope. In other studies that report such fluxes, the use of linear regression is often motivated by short closure times and careful analysis. Indeed, the good accordance with the results of the exponential model justifies the careful application of linear regression on the basis of the large spatial variability present in nature.

The NDFE model, however, exemplifies that flux estimates can be overestimated and noisy when the assumptions of a process-based model are violated. The NDFE model should only be applied with outmost care, i.e., only if the analyst is sure that the altered gas concentration gradient is indeed the main reason for curvilinear concentration changes, such as it might be in controlled laboratory experiments or computer simulations. Direct measurements of the gas concentration at different depths in the soil under a chamber could in future studies quantify to what extent the concentration gradient is really altered by the presence of the chamber.

It is moreover important that the used flux estimator is suitable for the resolution at which the primary gas concentrations are measured. The measurement precision in the present study was high enough for both time and concentration to perform an analysis of curvilinear behavior, and relevant information contained therein could be extracted. We have shown that the simultaneous measurement of $\mathrm{CH}_{4}$ and $\mathrm{CO}_{2}$ curvatures (as well as PAR) can be used to isolate leakage and estimate photosynthesis through its limitation by $\mathrm{CO}_{2}$ concentrations in the chamber headspace. Under stable, high PAR conditions this allows for $\mathrm{CO}_{2}$ flux partitioning, which is particularly relevant for high Arctic sites where nighttime data are not available in summertime. Old data sets can be used to further compare the partitioned $\mathrm{CO}_{2}$ fluxes of models to those derived from the measured curvatures. The potential of the curvature partitioning, as well as the large uncertainties still connected to it, provides an incentive for improvement in future measurement campaigns and analyses. The present study shows that the application of curvilinear models to high-resolution closed chamber measurements has the potential to provide additional insights to the different processes which give rise to the net gas flux in the chamber and govern ecosystem behavior at large.

\section{The Supplement related to this article is available online at doi:10.5194/bg-13-903-2016-supplement.}

Acknowledgements. The research leading to these results has received funding from the European Community's Seventh Framework Program (FP7) under grants 238366, 262693 and 282700, the Nordic Centers of Excellence DEFROST and eSTICC, as well as the GeoBasis programs supported by the Danish Energy Agency.

Edited by: S. M. Noe

\section{References}

Bäckstrand, K., Crill, P. M., Mastepanov, M., Christensen, T. R., and Bastviken, D.: Total hydrocarbon flux dynamics at a subarctic mire in northern Sweden, J. Geophys. Res.-Biogeo., 113, G03026, doi:10.1029/2008JG000703, 2008.

Farquhar, G., von Caemmerer, S. V., and Berry, J.: A biochemical model of photosynthetic $\mathrm{CO}_{2}$ assimilation in leaves of $\mathrm{C} 3$ species, Planta, 149, 78-90, 1980.

Forbrich, I., Kutzbach, L., Hormann, A., and Wilmking, M.: A comparison of linear and exponential regression for estimating diffusive $\mathrm{CH}_{4}$ fluxes by closed-chambers in peatlands, Soil Biol. Biochem., 42, 507-515, 2010

Goodrich, J. P., Varner, R. K., Frolking, S., Duncan, B. N., and Crill, P. M.: High-frequency measurements of methane ebullition over a growing season at a temperate peatland site, Geophys. Res. Lett., 38, L07404, doi:10.1029/2011GL046915, 2011.

Goulden, M. and Crill, P.: Automated measurements of $\mathrm{CO}_{2}$ exchange at the moss surface of a black spruce forest, Tree Physiol., 17, 537-542, 1997.

Healy, R. W., Striegl, R. G., Russell, T. F., Hutchinson, G. L., and Livingston, G. P.: Numerical Evaluation of Static-Chamber Measurements of Soil-Atmosphere Gas Exchange: Identification of Physical Processes, Soil Sci. Soc. Am. J., 60, 740-747, 1996.

Hutchinson, G. and Mosier, A.: Improved soil cover method for field measurement of nitrous oxide fluxes, Soil Sci. Soc. Am. J., 45, 311-316, 1981.

Jensen, L. M. and Rasch, M.: Nuuk Ecological Research Operations: 6th Annual Report 2012, Tech. rep., Aarhus University, DCE-Danish Centre for Environment and Energy, 2013.

Kutzbach, L., Schneider, J., Sachs, T., Giebels, M., Nykänen, H., Shurpali, N. J., Martikainen, P. J., Alm, J., and Wilmking, M.: $\mathrm{CO}_{2}$ flux determination by closed-chamber methods can be seriously biased by inappropriate application of linear regression, Biogeosciences, 4, 1005-1025, doi:10.5194/bg4-1005-2007, 2007.

Lasslop, G., Reichstein, M., Papale, D., Richardson, A. D., Arneth, A., Barr, A., Stoy, P., and Wohlfahrt, G.: Separation of net ecosystem exchange into assimilation and respiration using a light response curve approach: critical issues and global evaluation, Glob. Change Biol., 16, 187-208, 2010.

Levy, P., Gray, A., Leeson, S., Gaiawyn, J., Kelly, M., Cooper, M., Dinsmore, K., Jones, S., and Sheppard, L.: Quantification of uncertainty in trace gas fluxes measured by the static chamber method, Europ. J. Soil Sci., 62, 811-821, 2011. 
Livingston, G. P., Hutchinson, G. L., and Spartalian, K.: Diffusion theory improves chamber-based measurements of trace gas emissions, Geophys. Res. Lett., 32, L24817, doi:10.1029/2005GL024744, 2005.

Lund, M.: Peatlands at a Threshold: Greenhouse Gas Dynamics in a Changing Climate, Meddelanden från Lunds universitets Geografiska institution, Avhandlingar, 183, Lund University, 2009.

Mastepanov, M., Sigsgaard, C., Tagesson, T., Ström, L., Tamstorf, M. P., Lund, M., and Christensen, T. R.: Revisiting factors controlling methane emissions from high-Arctic tundra, Biogeosciences, 10, 5139-5158, doi:10.5194/bg-10-5139-2013, 2013.

McGuire, A. D., Christensen, T. R., Hayes, D., Heroult, A., Euskirchen, E., Kimball, J. S., Koven, C., Lafleur, P., Miller, P. A., Oechel, W., Peylin, P., Williams, M., and Yi, Y.: An assessment of the carbon balance of Arctic tundra: comparisons among observations, process models, and atmospheric inversions, Biogeosciences, 9, 3185-3204, doi:10.5194/bg-9-3185-2012, 2012.
Pedersen, A. R., Petersen, S. O., and Schelde, K.: A comprehensive approach to soil-atmosphere trace-gas flux estimation with static chambers, Europ. J. Soil Sci., 61, 888-902, 2010.

Ström, L., Mastepanov, M., and Christensen, T. R.: Species-specific effects of vascular plants on carbon turnover and methane emissions from wetlands, Biogeochemistry, 75, 65-82, 2005. 